\title{
Fenomenologia e psicologia da religião no Brasil: fundamentos, desafios e perspectivas
}

\author{
Phenomenology of Religion in Brazil: principles, \\ challenges and Perspectives
}

\section{Adriano Furtado Holanda*}

Universidade Federal do Paraná (UFPR), Curitiba, PR, Brasil

\section{Resumo}

Falar de religião é, fundamentalmente, falar de experiência religiosa, dado que a religião só existe porque há sujeitos que a manifestam de uma forma intencional. Esta é a posição da Fenomenologia, cuja tradição, inaugurada pelos estudos de Edmund Husserl, replica em parte o projeto de fundamentação radical das ciências e da filosofia que encontramos em Descartes, e faz com que o edifício fenomenológico venha a se erguer sobre múltiplas perspectivas: como epistemologia (ponto de partida), método (caminho), filosofia (construção) e ciência (intenção). A intenção deste trabalho é apresentar as raízes que desembocam no desenvolvimento de uma Fenomenologia da

AFH: Doutor em Psicologia, e-mail: aholanda@yahoo.com 
Religião, bem como suas premissas e autores fundamentais. Em seguida, pretende-se traçar breve panorama dos debates ora em pauta, sob a égide do pensamento fenomenológico, no contexto dos estudos sobre religião, religiosidade e espiritualidade, no Brasil. Pesquisas recentes são apresentadas, como ilustração dos desafios e perspectivas do campo. Por fim, vale destacar que fazer uma "fenomenologia" da religião passa por um olhar amplo para o fenômeno religioso, incluindo a análise do significado dos movimentos em religiões - trânsito religioso, migrações, etc. - além da interpretação de signos e sinais particulares. Conclui-se pela necessidade de se ampliar o debate e o desenvolvimento de pesquisas no campo, bem como estabelecer uma melhor compreensão do sentido de se fazer uma "fenomenologia".

Palavras-chave: Fenomenologia. Fenomenologia da Religião. Pesquisa. Saúde.

\section{Abstract}

Talking about religion implies talking about a religious experience. Religion exists only because there are individduals who intentionally manifest it. This is the classic position of Phenomenology, a tradition founded by Edmund Husserl, that replicates in some way the radical foundation project of science and philosophy found in Descartes, and which makes the phenomenological structure rise over multiple perspectives, such as epistemology, method, philosophy and science to name a few. This paper aims to discuss the roots that lead to a Phenomenology of Religion, as well as its assumptions and key authors. It also intends to draw an overview of current discussions within the aegis of the phenomenological thought in which studies about religion, religiosity and spirituality are concerned in Brazil. Recent researches are presented to illustrate the challenges and perspectives of the field. To finish, it is relevant to point out that a religious "phenomenology" goes through a broader view of the religious phenomenon, which includes the analysis of movements in religion and its meaning (migration, religious traffic) besides the interpretation of signs and specific symbols. It concludes to a need for more research and dialogues, and a better understanding of what is to be considered "phenomenology".

Keywords: Phenomenology. Phenomenology of Religion. Research. Health. 


\section{Introdução}

Falar de Religião é falar de "experiência religiosa", reconstituindo o objeto religioso em interação com um sujeito concreto. Neste contexto relacional, a Fenomenologia se coloca em contínuo diálogo com as demais ciências. O objetivo aqui é traçar um panorama e um entendimento do que seja uma Fenomenologia da Religião (FR) no campo da Psicologia da Religião, buscando compreender seus espaços de desenvolvimento no Brasil. Parte-se da ideia de Fenomenologia como a ciência dos fundamentos (HUSSERL, [1910] 1965, [1913], 1985, [1929], 1992), para um olhar ao fenômeno religioso; mantendo - por eleição - o sujeito por foco. Importa destacar aqui que a Fenomenologia não identifica o sujeito fenomenológico - como subjetividade transcendental e como intersubjetividade contextualizada - com o "sujeito psicológico", como também não o identifica com os demais "sujeitos" da ciência.

Principiaremos por uma narrativa dos diversos modos de compreensão de uma FR, para recompor o campo e dialogar com o cenário brasileiro ainda incipiente. As dificuldades do campo são inerentes a uma Fenomenologia, dado que a análise fenomenológica demanda uma mudança de posição, uma mudança de perspectiva. As análises fenomenológicas sobre "Deus" - entre aspas, para salvaguardar os diversos modos de articulação e os diversos modos de relacionamento com o sujeito humano - se dão por várias vias, como a filosófica (ou teorética), a religiosa ou a mística (e, no que nos diz respeito mais diretamente, igualmente pela via psicológica), e aparecem em toda sua complexidade (BELLO, 2016), convocando o estudioso ao enfrentamento da questão, numa direção quase que "necessária" - interdisciplinar, não prescindindo dos olhares da história, da cultura, da antropologia, da sociologia, dentre tantas outras. Como veremos, é sobre este rico solo da diversidade que se alicerça a análise fenomenológica da experiência religiosa. 


\section{A Tradição da Fenomenologia da Religião}

A posição fenomenológica é de que a religião somente se dá na manifestação, como experiência religiosa (vivência) frente ao mistério, ao sagrado e ao inexplicável. Nesta premissa constitui-se a dialética do exercício fenomenológico do olhar para a religião: é da essência do fenômeno religioso se mostrar e se mostrar a alguém, e é em relação a este "alguém" que aparece como (relativamente) oculto, se revelando progressivamente e (relativamente) transparente (VAN DER LEEUW, [1933] 1948). O "fato religioso" é tomado como realidade existencial, como fato histórico e também como objetividade passível de pesquisa empírica.

Rudolf Otto, contemporâneo de Husserl, é nome de destaque nesta tradição, por sua análise hermenêutico-fenomenológica da experiência religiosa, e sua descrição do Sagrado, como o mysterium tremendum et fascinans, e estabelece um vínculo antropológico às ciências da religião. É sua defesa do numinoso como essência universal que torna Otto um fenomenólogo. Mas é com Gerardus Van der Leeuw que a FR se constitui como um campo destacado de estudos, a partir da colocação da compreensão como arché e télos de seu método. O estudioso teria como tarefa primordial entrar em sintonia no plano afetivo com seu objeto.

[...] podemos considerar a religião como experiência vivida compreensível [...]; ou a fazer valer como revelação não-compreensível. A experiência vivida (na sua "reconstrução") é um fenômeno. A revelação não o é; mas a resposta que o homem dá à revelação, o que ele diz do que é revelado, isto também é um fenômeno, permitindo concluir indiretamente que há a revelação (per viam negationis)" (VAN DER LEEUW, [1933] 1948, p. 662).

O sentido religioso é o sentido do todo; é uma experiência vivida no limite, uma revelação que permanece oculta. Neste caso, "como cultivar a fenomenologia onde não há um fenômeno?” (VAN DER LEEUW, [1933] 1948, p.665). É exatamente esta antinomia - que diz respeito às religiões e à compreensão - que torna possível uma "ciência" da experiência religiosa. A fé não exclui a époche, nem a époche exclui a fé. É a duplex ordo agostiniana. Mas como compreender algo que escapa ao intelecto, e mesmo escapa à apreensão? Toda compreensão "até o fundo" cessa de ser 
uma, antes de haver alcançado o fundo: ela se reconhece como sendo compreendida, no lugar do compreender. Em outros termos, toda compreensão, não importa qual objeto à qual se dirige, é finalmente religiosa (VAN DER LEEUW, [1933] 1948, p.666). O campo da FR se põe num processo incessante de elucidação da experiência religiosa, cabendo-lhe a prerrogativa de acessar este sentido vivencial, e redescobrir o significado em sua totalidade; pressupõe aquele télos intencional, do qual falava Husserl, e a époche, que permite o acesso à intuição. Nesta direção, a FR encontra o existir como fundamento, enquanto "experiência originária da religiosidade" (HEIDEGGER, 2006).

\section{Concepções de Fenomenologia da Religião}

Tradicionalmente, portanto, a expressão FR remete a uma perspectiva de "olhar", a uma "fenomenologia religiosa". É pela via da Erlebnis - da experiência vivida, da vivência - que se dá o encontro da fenomenologia com a psicologia da religião. Essa experiência provoca no homem a sensação de estar defronte de uma experiência misteriosa, fascinante e temível (Otto), e apresenta uma faceta racional e outra irracional, "irredutível às categorias humanas e intraduzível na linguagem da analogia, correspondente à natureza misteriosa do 'inteiramente outro' que se manifesta na experiência religiosa” (PIAZZA, 1976, p. 11). Uma FR é, pois, uma tentativa de se compreender o significado do "fato religioso", como experiência (fato humano), tomado em "suas manifestações e expressões sensíveis, com a finalidade de apreender seu significado último” (p. 15). Assim, constitui-se numa pesquisa histórica, numa interpretação existencial e situa-se no campo da objetividade.

Numa perspectiva antropológica, é - nas palavras de Malinowski um fato universal, dado que não há povo, por mais primitivo que seja, sem religião. E como tal, deve ser estudado enquanto experiência vivida; e como fato objetivo, é passível de estudos empíricos e positivos, no sentido atribuído pelo próprio Husserl. Nesta perspectiva, somente a fenomenologia pode dar o conhecimento das realidades existenciais, pois o fenômeno tem um aspecto "transcendente" por estar alicerçado na compreensão de 
seu significado, que remete à consciência humana, e que remete ao movimento desta consciência voltada para o mundo.

\section{A Ideia de uma Fenomenologia da Religião}

Heidegger nos dá excelentes exemplos das possibilidades de uma FR. Em curso sobre "Os Fundamentos Filosóficos da Mística Medieval” (1918-1919), fornece uma elucidação fenomenológica da experiência mística. Já no inverno de 1920-1921, Heidegger escreve uma "Introdução à Fenomenologia da Religião", onde afirma que é preciso estabelecer o objeto da religião, devendo-se, primeiro, delimitar a experiência religiosa genuína e examinar o acesso adequado a ela. Heidegger elege como experiência religiosa autêntica a do cristianismo primitivo, e parte para a análise dos escritos paulinos. No verão de 1921, escreve a lição "Agostinho e o Neoplatonismo" - baseando-se no Livro X das Confissões. Esses textos apontam caminhos possíveis que uma FR pode trilhar, mesmo que em disputa com o método husserliano, marcando diferenças com os demais "fenomenólogos da religião", como Reinach, Scheler, Stavenhagen, e Van der Leeuw (USCATESCU, 2006). Essas distinções conceituais, devem-se, em parte, à relevância que a teologia ocupa "na proveniência e no porvir de seu [Heidegger] pensar" (FERNANDES, 2015, p. 95), e envolve a questão do ser e da linguagem, levando Heidegger a definir a Fenomenologia como:

[...] a via de acesso e o modo de comprovação para se determinar o que deve constituir tema da ontologia. Ontologia só é possível como fenomenologia. [...] Em seu conteúdo, a fenomenologia é a ciência do ser dos entes - é ontologia [...] Da própria investigação resulta que o sentido metodológico da descrição fenomenológica é interpretação. O logos da fenomenologia da presença possui o caráter de hermeneuein (apud FERNANDES, 2015, p. 96).

A época na qual Heidegger discute essas questões já havia conhecido importantes trabalhos na História das Religiões: em 1890, Codrington comunica o conceito de "mana"; entre 1900-1920, Wundt produz sua Völkerpsychologie, apontando o totemismo como a primeira 
forma de religião; Otto, em 1917, aponta o sagrado como o principal objeto da religião. Nesse solo fértil se desenvolve a questão fenomenológica, mas Heidegger não é o primeiro a se ocupar do tema na Fenomenologia: Husserl, nas Ideen, em 1913, aponta Deus como o princípio teleológico (BELLO, 2016); igualmente Scheler, com sua Vom Ewigen im Menschen, de 1921, além de Reinach, que escreve esboços de uma FR entre 1915 e 1917.

Qual é a fenomenologia da religião de Heidegger? Heidegger não mira a religião na sua totalidade, nem a experiência de Deus, mas se centra na "experiência originária da religiosidade", e centra sua atenção sobre a vida fáctica que têm Paulo e Agostinho. Ao analisar a vida de Paulo - como experiência vital de um crente - , Heidegger põe em relevo sua situação articulada no seu mundo próprio (Selbstewelt), no seu mundo partilhado ou co-mundo (Mitwelt) e em seu mundo circundante (Umwelt); ressalta a proclamação evangélica no que se proclama (no seu sentido de conteúdo), no Gehaltssinn; num sentido referencial da proclamação (Bezugssinn); no a quem se proclama e donde se proclama, importando, sobretudo, o como da proclamação, que é o sentido executivo (Vollzugssinn). O sentido referencial da vida fáctica cristã, que não é senão a expectativa ou a esperança da vinda do Cristo - é a $\pi \alpha \rho o v \sigma i ́ \alpha$ (" $p a$ -

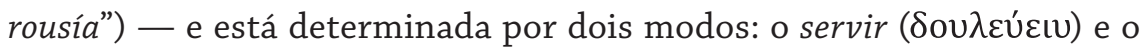

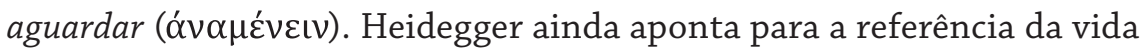
fáctica cristã, como um "peculiar estar diante de Deus", como expectativa de vinda no futuro, no "final dos tempos", o que designa a peculiar temporalidade da vida cristã como um "ainda não".

\section{As Escolas Fenomenológicas da Religião}

A expressão FR foi criada por Pierre Daniel Chantepie de la Saussaye (1848-1920), a partir da primeira edição de seu Lehrbuch der Religionsgeschichte (SAUSSAYE, [1887] 1940), introduzindo o momento sistemático da disciplina. A história das religiões - além de estudar a unidade da religião em sua multiplicidade - deveria igualmente evidenciar os aspectos permanentes da religião, o que poderia ser obtido por 
meio do método comparativo, permitindo classificar e organizar grupos de manifestações religiosas, em suas diversas facetas (objeto, natureza, tipos de mitos, etc.). Nova denominação para as "religiões comparadas", numa direção semelhante à tomada pelos estudos de Lineu. Chantepie de la Saussaye propõe nova palavra de ordem para um modo de pesquisas sistemático das religiões.

Desse modo, a Comparative Religion de caráter evolucionista, como ensinam os casos exemplares de Tylor ou de Frazer, propunha-se evidenciar os tipos recorrentes de crenças e rituais religiosos, estabelecer sua ordem evolutiva, de modo que permite que se respondesse à pergunta fundamental, que dominava todas as pesquisas da época: qual é a origem da religião (FILORAMO; PRANDI, 1999, p. 28).

\section{A Virada Fenomenológica}

Num primeiro momento, a FR é uma "análise descritiva e sistemática" dos fenômenos religiosos. A virada se dá com Husserl, num esforço anti-metafísico, realista, de "voltar às coisas-mesmas", no esteio das reflexões de Dilthey sobre a autonomia das ciências do espírito, quando este afirma a necessidade da adequação do método para a apreensão do "mundo das produções culturais". A Erlebnis não pode ser definida, mas pode ser experimentada e descrita; a virada se dá na construção não apenas de uma abordagem descritiva, mas hermeneuticamente orientada (DILTHEY, [1894] 2002); e se apresenta, em sua mais conhecida expressão, na obra de Van der Leeuw.

\section{A Fenomenologia de Van der Leeuw}

O nome de Gerardus Van der Leeuw (1890-1950) melhor se dá a conhecer através de sua obra de 1933, Phanomenologie der Religion como um manifesto da fenomenologia compreensiva. "A compreensão (Verstehen) é o arché e o telos do seu método fenomenológico. A primeira 
função do estudioso, de fato, é entrar em sintonia, no plano afetivo, com o objeto (Einfühlung)" (FILORAMO, PRANDI, 1999, p. 32). Nesse caminho, Van der Leeuw afirma: “o que as ciências da religião chamam 'objeto' da religião é para a religião mesma seu 'sujeito”' (VAN DER LEEUW, [1933] 1948, p. 9).

A fenomenologia busca o fenômeno. O que é o fenômeno? É o que se mostra. Isto comporta uma tripla afirmação: $1^{\circ}$ Há qualquer coisa; $2^{\circ}$ esta coisa se mostra; $3^{\circ}$ é um fenômeno pelo fato mesmo que se mostra. Ora, o fato de se mostrar diz respeito tanto ao que se mostra, quanto àquele a quem isto se mostra. O fenômeno, por conseguinte, não é um simples objeto; ele não é nem mesmo $o$ objeto, a realidade verdadeira, cuja essência seria somente recoberta pela aparência das coisas vistas. Isto ressalta uma certa metafísica. Por "fenômeno" não se entende mais qualquer coisa de puramente subjetivo, uma "vida" do sujeito, que estuda uma parte distinta da psicologia - por mais que haja a possibilidade. Mas o fenômeno é, ao mesmo tempo, um objeto que se reporta ao sujeito e um sujeito que se refere ao objeto. [...] Toda sua essência consiste em se mostrar, se mostrar a "alguém". Tão logo esse "alguém" comece a falar do que se mostra, faz-se a fenomenologia (VAN DER LEEUW, [1933] 1948, p. 654).

\section{A Tradição Fenomenológica Alemã: A "Escola de Marburg"}

A FR de Van der Leeuw aponta para a autonomia da religião, recorrendo às "correntes culturais alemãs", desde a fenomenologia de Husserl e Scheler, a hermenêutica de Dilthey, a filosofia da vida de Simmel, a psicopatologia de Jaspers e a psiquiatria existencial de Binswanger "que melhor se prestavam a evidenciar o dado existencial da religião, a sua natureza de experiência consubstancial à natureza mesma do homem. Nessa perspectiva, o homem é naturaliter religioso" (FILORAMO, PRANDI, 1999, p. 36). Após Van der Leeuw, surgiram críticas ao modelo da fenomenologia compreensiva, particularmente entre os representantes da Escola de Marburg - iniciada por Rudolf Otto - que oferecem um "modelo de análise hermenêutica fenomenológica da experiência religiosa" (FILORAMO \& PRANDI, 1999, p. 37). 
Rudolf Otto (1869-1937), teólogo protestante e grande conhecedor de religiões comparadas, publica em 1917 um texto que viria a ser central no estudo das religiões: Das Heilige ("O Sagrado"), um dos mais importantes tratados em língua alemã do século XX, no qual cunha o termo numinoso, para designar o caráter da experiência religiosa "para além” do racional, superior, e que inspira terror e temor, além de fascínio e maravilha. "O numinoso singulariza-se como qualquer coisa de ganz andere, radical e totalmente diferente" (ELIADE, [1957], 1965, p. 16), algo de "Totalmente Outro", de radicalmente "alter" ao homem. Nesta obra, estuda a "experiência religiosa", sobretudo por seu lado irracional, "[...] pois tinha lido Lutero e compreendera o que quer dizer, para um crente, o 'Deus vivo'. Não era o Deus dos filósofos, [...]; não era uma idéia, uma noção abstrata, uma simples alegoria moral. Era, pelo contrário, um poder terrível, manifestado na 'cólera' divina” (ELIADE, [1978] 1983, p.15).

Foram diversos seus alunos que se dispuseram a pesquisar o método para compreender a essência do fenômeno religioso. Um nome a destacar é o de Friedrich Heiler (1892-1967), teólogo e historiador alemão, que foi professor em Marburg, e que publica um texto sobre a essência da religião, em 1961 (Erscheinungsformen und Wesen der Religion), dizendo que "os fenômenos são apenas investigados pelo conhecimento da essência que está na sua base e que tem de ser focada. Nunca se deve parar nas suas cascas internas, mas tem-se de penetrar através delas para chegar ao seu núcleo, que é a experiência religiosa" (HEILER, apud GRESCHAT, 2005, p. 139). Como fundamento verdadeiramente fenomenológico da perspectiva de Heiler, o que se destaca é que a Religião é, antes de tudo, Handlung ou ação, e Erlebnis, experiência vivida. Outros autores da Escola de Marburg deixaram importantes contribuições ao campo, como Gustav Mensching (1901-1978), autor de numerosas monografias fenomenológicas, que aponta para a pesquisa fenomenológica em dois níveis: uma função de comparação das religiões (com o intuito de evidenciar suas afinidades tipológicas e estruturais), e uma função de compreensão de sua essência, que é a experiência do encontro com o Sagrado. Além de Kurt Goldammer e de Günter Lanczkowski, para quem a FR é uma Religionwissenschaft. 


\section{Fenomenologia da Religião na Holanda}

A escola fenomenológica holandesa representa o estudo sistemático dos fatos religiosos (desde suas origens). Termina por confundir-se, enquanto FR, com a história das religiões. No campo dos estudos de psicologia da religião, as universidades holandesas representam parcela significativa na produção acadêmica contemporânea (PAIVA, 2004). Um dos mais importantes nomes desta escola é Carl Bleeker, para quem a FR é uma ciência empírico-indutiva, sem objetivos filosóficos. "Para alcançar esse objetivo final, ela persegue três objetivos: desenvolver a theoria dos fenômenos, procurar o logos, interrogar-se sobre sua entelechia" (FILORAMO, PRANDI, 1999, p. 46). Bleeker ilustra as dificuldades e as contradições do método fenomenológico que, não querendo se isolar no puramente descritivo, busca interrogações de cunho existencial, experiencial e essencial.

\section{Fenomenologia na obra de Mircea Eliade}

Um derradeiro destaque ao qual não podemos nos furtar é a apresentação de Mircea Eliade: historiador, "mitólogo", filósofo e romancista, nasceu em Bucareste, Romênia, em 1907, e faleceu em Chicago, em 1986. Chegou a viver na Índia entre 1928 e 1932, quando preparou sua tese sobre yoga. Foi adido cultural em Londres e Lisboa, passando a lecionar na École des Hautes Études em Paris, a partir de 1945. De 1957 até sua morte, ocupou a cadeira de titular de História das Religiões em Chicago (ELIADE, [1957] 1965).

Além de erudito, era versado em diversas línguas, como o alemão, o italiano, o hebreu, o persa e o sânscrito, Eliade pode ser considerado um dos fundadores da moderna História das Religiões. A partir de seus estudos sobre os mitos, elabora uma concepção de religiões comparadas, buscando as relações de proximidade entre as culturas e os momentos históricos. Tal qual Otto aponta que o centro da experiência religiosa do homem é a ideia de sagrado, e um dos conceitos que se destaca de sua obra é o de Hierofania, ou a manifestação do transcendente num objeto ou fenômeno ou, simplesmente, o aparecimento ou manifestação reveladora do sagrado. Na tradição grega, "hierofante" era aquele que dava a conhecer o sagrado, ou seja, o 
encarregado de instruir os iniciantes nos mistérios, no oráculo e no culto. Era especialmente o nome dado ao sacerdote que presidia a iniciação nos mistérios de Elêusis.

O tema do "sagrado" é trabalhado em uma de suas mais importantes obras: O Sagrado e o Profano, que define como uma "introdução geral ao estudo fenomenológico e histórico dos fatos religiosos" (ELIADE, [1957] 1965, p. 9). Outra importante obra é o seu Tratado de História das Religiões (de 1949), na qual traça um estudo de morfologia religiosa. Compilador de tradições, talvez sua obra mais conhecida seja História das Crenças e das Ideias Religiosas, publicado já na década de 1970.

Sua FR está associada a três princípios metodológicos fundamentais (MENDONÇA, 2012): a irredutibilidade do fenômeno religioso (que postula a necessidade de se estudar esse fenômeno no seu próprio plano de significação); a dialética do sagrado e do profano (que conduz o pesquisador a apreender a intencionalidade do fenômeno religioso), e; a teoria do simbolismo religioso (que é o instrumento que permite a compreensão do fenômeno religioso). Sua "virada hermenêutica" guarda proximidade com a tradição compreensiva da fenomenologia religiosa. O sagrado, em Eliade, é não apenas o objeto do conhecimento, mas igualmente o sujeito e o meio do seu conhecimento. "Para o historiador das religiões, toda manifestação do sagrado é importante; todo rito, mito, crença ou figura divina reflete a experiência do sagrado, e por conseguinte, implica as noções de ser de significação e de verdade" (ELIADE, [1978] 1983, p. 13).

Embora seja um caminho não exaustivo, há outros debates e correlações possíveis entre Ciências da Religião e a FR, bastando, para tal, observarmos as "pontes" com o pensamento de Paul Tillich (GOTO, 2011). É importante reconhecermos que o que "marca" ou representa o "espírito" da fenomenologia é a questão do sentido ou da significação.

\section{Fenomenologia da Religião no Panorama Atual}

Retomemos Van der Leeuw, no que "fazer fenomenologia, é falar do que se mostra": 
Consequentemente, em relação ao "alguém" a quem ele se mostra, o fenômeno comporta três características fenomenais superpostas: $1^{\circ}$ ele é (relativamente) oculto; $2^{\circ}$ ele se revela progressivamente; $3^{\circ}$ ele é (relativamente) transparente. Essas etapas superpostas não são iguais, mas correlativas àquelas da vida: $1^{\circ}$ experiência experimentada, vivida; $2^{\circ}$ compreensão, $3^{\circ}$ testemunho. Os dois últimos tópicos, cientificamente tratados, constituem o trabalho da fenomenologia (VAN DER LEEUW, [1933] 1948, p. 654).

Ora, uma das dimensões da FR é "buscar a Deus e buscar saber o que é Deus" (BELLO, 2016), numa reflexão intelectual. Embora partamos da premissa que a fenomenologia é uma só, há, evidentemente, diferentes apropriações por parte das várias modalidades científicas, como Teologia, Sociologia, Psicologia, dentre outras. Assim, há que se notar perspectivas distintas sobre o mesmo escopo, e reconhecer que o discurso filosófico, bem como seu objeto, é diferente da apropriação da Teologia ou da Psicologia, por exemplo. Nesta direção, o debate provocado pela análise das diferenças de apropriações da FR no Brasil e Alemanha, como são percebidas e avaliadas distintamente, é relevante (BRANDT, 2006).

Por meio de um olhar sobre os manuais de ciências da religião que, na Alemanha representam uma longa realidade, e no Brasil não são mais do que "intenções" - Brandt (2006) mostra como que a FR foi "despachada" para o rol das perspectivas históricas ultrapassadas, vista como mera pesquisa no contexto da história das religiões (HR); mas aponta para a FR como "a origem genuína das ciências da religião mais recentes; [...] como principium da ciência da religião. Mas pode significar também que o início da ciência da religião na FR está ultrapassado pelos acessos posteriores" (BRANDT, 2006, p. 126).

Num primeiro aporte, a identificação em FR e HR aponta para significativas limitações de apropriação; afinal, tanto a HR como a História Comparada das Religiões serviram (e servem) como importantes recursos de conhecimento, análise e interlocução entre as diferentes manifestações religiosas, auxiliando sobremaneira no diálogo interdisciplinar. Desta feita, uma leitura das manifestações religiosas se configura em verdadeira e concreta possibilidade de superação de pressupostos que o acesso ao conhecimento privilegia; auxilia no diálogo, na medida em que busca encontrar tanto paralelos quanto dissonâncias que certificam a realidade do 
acesso ao fenômeno religioso como manifestação humana e mundana. Noutra direção, esta identificação a que nos reportamos aqui ainda aponta para críticas de "aspectos" - muitos deles distintivos - relacionados a autores tradicionais da FR e não à totalidade do sentido de suas contribuições (USARSKI, 2004; BRANDT, 2006).

Outra das críticas importantes repousa sobre a posição de relevância que sistematicamente um conceito toma, quando se analisa particularmente o rol de autores associados à FR. Assim, "contra Söderblom, Otto e Van der Leeuw se objeta que eles postulam uma categoria específica - a do sagrado ou a do poder - e as respectivas experiências religiosas para descrever a essência da religião com base nesse fundamento" (BRANDT, 2006, p. 127); o mesmo valendo para Eliade quando entende que todas as religiões remetem a um ser em si. Brandt (2006) aponta ainda para a interpretação da FR como uma "ciência atemporal da religião", o que equivaleria a desconectá-la dos múltiplos sentidos mutantes da realidade, além de suas múltiplas conexões com o tempo, cultura, etc. Há, aqui, uma crítica ao "genérico" ou à "generalidade" (associada à noção de "essência”?!), apontando que se ontologiza o transcendente — ou seja, quando Otto fala do numinoso, quando Eliade fala da irrupção do sagrado no profano, ou mesmo quando Jung estabelece um conjunto de símbolos arquetípicos, eles estariam numa linha de ontologização que desconsideraria o elemento narrativo e os contextos sociais das religiões.

A partir dessa linha, toma-se a proposição geral de um FR por simplificação positiva, associando-a a repertórios estanques de análise que descontextualizam a história (e sua história). Não apenas a FR não é uma disciplina a-histórica (ou a-teórica ou a-social, etc.), como é exatamente sobre esta dinamicidade de apresentações que o seu objeto se constitui. O fenômeno (religioso) não é o "aparecer" de um objeto (ou de um algo), mas o "aparecendo", o "acontecimento" que se dá no entrelaçamento, na multiplicidade das apresentações de um ser (sujeito), que igualmente não pode ser confundido com uma "entidade" autônoma ou isolada. Em boa parte dessas críticas encontramos eco da própria questão de Merleau-Ponty, quando anuncia aos incautos que se apropriam da Fenomenologia numa perspectiva meramente positivista (como "fenomenologismo"), que não se pode confundir o objeto percebido com o próprio ato perceptivo, bem 
como não se pode confundir o sujeito fenomênico com um suposto "sujeito” psicológico. Na direção contrária, propõem-se uma FR reflexiva em diálogo multidimensional (com ciências afins). Ora, mas este sempre foi o caráter primário da Fenomenologia: o diálogo, a múltipla consideração, os múltiplos aportes. Fenomenologia é abertura, despojamento, desalojamento, disposição.

No contexto alemão, pois, a avaliação da FR se dá num espectro que varia de uma "rejeição decidida até uma refundamentação cautelosa sob determinadas condições" (BRANDT, 2006, p. 130), ao passo que no Brasil, o cenário é totalmente outro, cenário que a coloca como "portadora de esperança das ciências da religião", visto seu discurso se apresentar disseminado de forma ampla, sendo o termo utilizado, por vezes, sem nenhuma reflexão metodológica especial. Além disso, depreende-se que, pelo fato do discurso filosófico ter significativa influência sobre as Ciências Humanas, passa-se a usar o termo "fenomenologia" de forma decorativa, num uso irrefletido que pressupõe a colocação da fenomenologia como "um termo de conhecimento geral" (p. 131).

Reconhecendo a realidade de um uso "irrefletido" do termo - que muitas vezes banaliza a proposta fenomenológica — há que se ressaltar, por outro lado, que nos parece um erro comum (particularmente no contexto da psicologia) a identificação da Fenomenologia com uma prática ou modelo metodológico (invariavelmente associado a um ou mais modelos de "método" de coleta e análise de dados empíricos de caráter qualitativo). Tornar a fenomenologia uma instrumentalidade é limitante e contraditória a sua própria crítica. Não há como se fazer fenomenologia sem uma reflexão epistemológica diretamente associada. Mesmo assim há constante identificação da Fenomenologia com uma metodologia. Como ciência dos fundamentos, a Fenomenologia serviria de estrutura para estabelecer a autonomia das ciências da religião. Mas, no cenário brasileiro - e, devido à irreflexão de seu uso - ela é tomada positivamente como um finalismo que beira a simplificação de todo um campo de estudos em seu escopo, como o "coroamento" e a consumação de todas as ciências da religião (BRANDT, 2006).

Observe-se que a positividade da tomada da FR no Brasil a coloca em situação de grande fragilidade, por sua irreflexão, e de não poder se 
aprofundar nas particularidades de sua contribuição, uma delas - fundamental - que seria o estudo sistemático dos grandes textos e autores filosóficos, o que tornaria a FR no Brasil num "centro vital" das ciências da religião (BRANDT, 2006), mesmo que no Brasil não se tenha dado um tratamento detalhado e aprofundado à disciplina (DREHER, 2003). Colocase, assim, a FR na condição de um "elo de ligação" entre as ciências, fragilizando suas contribuições e colocando-a na posição de uma "alternativa" não autônoma da qual não pode comportar.

\section{Desafios de uma Fenomenologia e de uma Psicologia da Religião no Brasil}

Um dos desafios em comum entre FR e PR no Brasil e na Alemanha é o fato de haver excessiva dependência, tanto de outras ciências, como de espaços de pesquisa e interlocução; além da dependência das próprias religiões e igrejas cristãs (BRANDT, 2006). É o caso particular do Brasil, onde não encontramos grande destaque (ou mesmo espaço) para estudos e pesquisas no contexto acadêmico. Basta, para tal, observarmos que no âmbito da Psicologia brasileira não há nenhum programa de graduação que, em seu cúrriculo, contemple uma disciplina sobre o tema da Psicologia da Religião. Quando muito a encontramos no rol das optativas das universidades públicas, mas que nem sempre conseguem vir à luz. "No que diz respeito ao Brasil, o lugar mais seguro da ciência da religião parece ser (ainda?) sob o teto da teologia cristã" (BRANDT, 2006, p. 141). Entretanto, o cenário da PR no Brasil é de grande produção e de ampliação de debates, com perspectivas positivas, em particular graças ao Grupo de Trabalho "Psicologia \& Religião" da ANPEPP, constituído em 1998, congregando pesquisadores de diversos programas de Pós-Graduação do país e, que realiza bianualmente um Seminário em torno de suas pesquisas (ESPERANDIO; MARQUES, 2015).

Mesmo assim, os desafios são múltiplos. Retomando Brandt (2006), dois deles são particularmente importantes: a ausência de grandes compilações - sejam manuais ou compêndios — que toquem em questões teóricas, metodológicas e conceituais relativas às Ciências da Religião e à 
Psicologia da Religião, e a igual ausência de tradução dos grandes clássicos. A polêmica em torno da tradução do texto de Otto, O Sagrado, ilustra bem essa questão. Mesmo assim, há que se destacar outros problemas. No caso específico da PR, o clássico de William James, Variedades da Experiência Religiosa, encontra-se esgotado há décadas; Edwin Starbuck é praticamente desconhecido; bem como Leuba, Stanley Hall, Allport, Argyle, Fowler e outros. A própria contribuição de Wundt fica limitada ao formalismo sob o qual é apresentado nos livros de história da psicologia.

Desta forma, não é de se espantar que o discurso "religioso" se confunda com o discurso científico ou filosófico sobre a religião, a religiosidade e a espiritualidade. E, com isto, se alienem as discussões no próprio seio da formação e da profissão no Brasil, como podemos observar claramente a partir da polêmica recente em torno da "laicidade" da profissão. Esta questão é importante - não apenas por considerarmos incoerente uma perspectiva "psicológica" que exclui o fato concreto da constituição das subjetividades, como é o caso da religiosidade — mas para trazermos a ideia do espírito da cooperação — da "hospitalidade" no sentido derridariano, do diálogo, do respeito e consideração pela diversidade, pelo apelo ao concreto, sem esquecer seu fundamento último, qual seja, o de um sujeito em intrínseca relação contextualizado, delimitado e aberto ao mundo. Quando se aliena o debate no seio de uma profissão, aliena-se o próprio fundamento da liberdade de pensar de seus sujeitos. O silenciamento ou a invisibilidade da religiosidade num determinado contexto, está a serviço de que ou de quem? Afinal, colocar a laicidade como pauta definida, numa defesa intransigente, já induz o caminho do debate. Bastaria apontar a posição de Habermas (2007), quando fala da dialética da razão comunicativa e defende que a legitimação do espaço democrático e do direito requer a participação de todos no debate público na tomada de decisões, numa "solidariedade respeitosa".

Um grande desafio da FR é reconhecer as próprias palavras de Husserl, quando define sua Fenomenologia Pura como a ciência dos fundamentos ou ciência fundamental (HUSSERL, [1913], 1985), como uma ciência dos fenômenos (de todas as ciências), em todas as suas manifestações. Portanto, poderíamos designar a Fenomenologia como a ciência da inclusão; pautada sobre a Einstellung, como uma (nova) orientação, 
uma atitude, um modo de ver aberto, distinto do modo naturalista. Em outras palavras, num (novo) modo de se pensar o diferente. A questão da radicalização da laicidade no contexto da PR brasileira escamoteia o "fenômeno" religioso que brota em múltiplas manifestações, e aliena uma realidade existencial profundamente arraigada do povo brasileiro. Desta feita, não há estudo da subjetividade e de seus processos de subjetivação que possa persistir sem considerar a dimensão essencialmente religiosa do brasileiro.

Por fim, convém assinalar os desafios empíricos e metodológicos da FR no Brasil. E um desses é exatamente a reconstituição do caráter do "empírico" no contexto da Fenomenologia, em seu sentido original - experiência - que tanto pode implicar numa pesquisa experiencial quanto experimental. Encontramos poucos estudos em PR que se apropriam do olhar fenomenológico. A expressão "FR" é pouco utilizada no contexto da Psicologia, bem como no próprio contexto das disciplinas de saúde em geral. Numa busca em bases de dados abertas — SCIELO e PePSIC — de publicações brasileiras, utilizando múltiplas associações entre descritores ("fenomenologia", "religião", "religiosidade”, "experiência religiosa", "vivência religiosa”, "espiritualidade”), o número de produções foi bem pouco expressivo, apenas 23 artigos, sendo que a maioria das produções se apoia em debates teóricos ou conceituais. A perspectiva de pesquisa fenomenológica exige a consideração de todas as manifestações do sujeito, como apresentações de um sujeito em sua íntima relação com o mundo. Assim, não há conflito entre o empírico, o experiencial e o subjetivo.

Na prática, o foco das pesquisas com o vivido do fenômeno religioso, a partir de seus diversos modos de apresentação podem ganhar contornos variados. Pode-se ouvir tanto fiéis e crentes, numa direção (ou sujeitos comuns, sem vínculo especial com religiosidades particulares), e profissionais, noutra direção (como sacerdotes e psicólogos), com o intuito de compreender como lidam com as dimensões do sagrado e do "profano", do espiritual e do secular. Isto significa acolher o fenômeno religioso em suas múltiplas manifestações, o que abre nosso "objeto" de estudo em várias perspectivas. Em recente pesquisa sobre a utilização do Coping Religioso/Espiritual por profissionais atuantes no contexto da Rede de Atenção Psicossocial (CORRÊA, HOLANDA, 2015), constatou-se sua alta 
utilização - tanto no âmbito pessoal, como no do trabalho, a partir das falas dos colaboradores - e uma pontuação baixa de fatores negativos do coping, apontando a esfera religiosa como relevante.

A leitura desses dados, bem como de outros dados derivados de pesquisas, nos faz refletir cada vez mais sobre a relevância do debate em torno do reconhecimento da experiência religiosa como uma manifestação autêntica do existente em seu contínuo diálogo com o mundo. Mesmo assim, o campo da Psicologia aliena cada vez mais essa experiência, não a reconhecendo como manifestação autêntica - social, individual ou antropológica - posicionando-se, assim, numa incoerência digna de nota: afinal, aquela disciplina que deveria privilegiar um olhar ampliado e isento para o sujeito humano é exatamente a que o retira de seu mundo e que o isola em perspectivas ideológicas alheias a si mesmo.

Por fim, vale destacar que fazer uma Fenomenologia da religião passa por um olhar amplo para o fenômeno religioso, incluindo a análise do significado dos movimentos em religiões — trânsito religioso, migrações, etc. - além da interpretação de signos e sinais particulares. Parece-nos que o que falta, para que se desenvolvam mais pesquisas em FR, seja exatamente uma melhor compreensão do sentido de se fazer uma "fenomenologia".

\section{Referências}

BELlO, A. A. Edmund Husserl. Pensar Deus, Crer em Deus. São Paulo: Paulus, 2016.

BRANDT, H. As Ciências da Religião numa Perspectiva Intercultural. A percepção oposta da fenomenologia da religião no Brasil e na Alemanha. Estudos Teológicos, v. 46, n. 1, p. 122-151, 2006.

CORRÊA, C. V; HOLANDA, A. F. Coping Religioso/Espiritual em Profissionais da Atenção à Saúde Mental do Litoral do Paraná. 2015. Dissertação (Mestrado em Psicologia) - Universidade Federal do Paraná, Curitiba, 2015.

DILTHEY, W. Psicologia e Compreensão. Ideias para uma psicologia descritiva e analítica. Lisboa: Edições 70, 2002 [1894]. 
DREHER, L. H. (Org.). A Essência Manifesta: A fenomenologia nos estudos interdisciplinares da religião. Juiz de Fora: Editora UFJF, 2003.

ELIADE, M. História das Crenças e das Ideias Religiosas. Rio de Janeiro: Zahar Editores, [1978] 1983.

ELIADE, M. Le Sacré et le Profane. Paris: Gallimard, 1965 [1957].

ESPERANDIO, M. R. G.; MARQUES, L.F. The Psychology of Religion in Brazil. The International Journal for the Psychology of Religion. v. 25, n. 4, p. 255-271, 2015.

FERNANDES, M. A. Fenomenologia e Teologia em Martin Heidegger. Reflexão, Campinas, v. 40, n. 1, p. 95-108, 2015.

FILORAMO, G.; PRANDI, C. As Ciências da Religião. São Paulo: Paulus, 1999.

GOTO, T. A. Fenomenologia e Experiência Religiosa em Paul Tillich. Revista da Abordagem Gestáltica, v. 17, n. 2, p. 137-142, 2011.

GRESCHAT, J-H. O Que é Ciência da Religião? São Paulo: Paulinas, 2005.

HABERMAS, J. Entre Naturalismo e Religião: estudos filosóficos. Rio de Janeiro: Tempo Brasileiro, 2007.

HEIDEGGER, M. Introducción a la Fenomenología de la Religión. México: Siruela, 2006.

HUSSERL, E. Conferências de Paris. Lisboa: Edições 70, 1992 [1929].

HUSSERL, E. Filosofia como Ciência de Rigor. Coimbra: Atlântida, 1965 [1910].

HUSSERL, E. Idées Directrices pour une Phénoménologie et une Philosophie Phénoménologie Pures. Paris: Gallimard, 1985 [1913].

MENDONÇA, M.L.V.P. A Concepção Eliadiana da Fenomenologia da Religião sob a Perspectiva do Método. Dissertação (Mestrado em Filosofia) - Faculdade Jesuíta de Filosofia e Teologia, Belo Horizonte, 2012.

PAIVA, G. J. Psicologias da Religião na Europa, Revisitadas. In: HOLANDA, A. F. (Org.). Psicologia, Religiosidade e Fenomenologia. Campinas: Editora Átomo, 2004. p. 37-46. 
PIAZZA, W. O. Introdução à Fenomenologia Religiosa. Petrópolis: Vozes, 1976.

SAUSSAYE, C. de la. História das Religiões. Lisboa: Inquérito, 1940 [1887].

USARSKI, F. Os Enganos sobre o Sagrado - Uma Síntese da Crítica ao Ramo "Clássico" da Fenomenologia da Religião e seus Conceitos-Chave. Rever - Revista de Estudos da Religião, n. 4, p. 73-95, 2004.

USCATESCU, J. Acerca de la fenomenología de la religión en las lecciones de Heidegger sobre la fenomenología de la vida religiosa. In: HEIDEGGER, M. Introducción a la Fenomenología de la Religión. México: Siruela. 2006. p. 09-30.

VAN DER LEEUW, G. A Religião em sua Essência e suas Manifestações. Fenomenologia da Religião - Epílogo. Revista da Abordagem Gestáltica, v. 15, n. 2, p. 179-183, 2009.

VAN DER LEEUW, G. La Religion dans son Essence et ses Manifestations. Phénoménologie de la Religion, Paris: Payot, 1948.

Recebido: 03/11/2016

Received: 11/03/2017

Aprovado: 25/02/2017

Approved: 02/25/2017 
